\title{
Costing Information System Design for a Clinic Registered as a First-Degree Healthcare Provider (Case Study: Ismal Medika Health Clinic)
}

\author{
Gamal Batara Department \\ of Accounting Universitas \\ Indonesia Jakarta, \\ Indonesia \\ gamal.batara@gmail.com
}

\author{
Machmudin Eka Prasetya \\ Department of Accounting \\ Universitas Indonesia \\ Jakarta, Indonesia \\ machmudin.prasetya@gmail.com
}

\begin{abstract}
This study aims to analyze and design a costing information system for Ismail Medika Health Clinic, registered as a first-degree health clinic in Badan Penyelenggara Jaminan Sosial or BPJS (the Indonesian Social Insurance Administration Organization). The Indonesian Ministry of Health suggests that healthcare providers need to contain their costs and at the same time maintain health care delivery quality. But since the clinic did not have a costing system, the manager could not obtain relevant and reliable patient care cost information, such that costs became untraceable. This case study uses a qualitative method. Data was acquired by interviews, document analysis, and observation. We used activity-based costing (ABC) as a healthcare cost allocation method. The framework for the application of systems technique (FAST) method was used to analyze and design the system requirements. The results of this study are the system logical design models that emerged into the clinic costing information system. Following the logical models results, the system then needed to be physically developed and will be used by clinic continuously for cost containment and other cost information-based decision making.
\end{abstract}

Keywords: costing information system; activity-based costing; first-degree healthcare provider

\section{INTRODUCTION}

The purpose of this study is to analyze and design a costing information system for Ismail Medika health clinic. As a firstdegree healthcare provider, every month the clinic receives capitation fund from BPJS Kesehatan-an Indonesian healthcare insurance organization. The amount of capitation fund paid to the clinic is determined by the number of BPJS patients registered at the clinic multiplied by a capitation rate, which is Rp 10,000 per patient for Ismail Medika Clinic. This capitation is meant to cover the medical cost of BPJS patients visiting the clinic. The problem is that the number of BPJS patients visiting the clinic fluctuates every month.

Without a costing system, clinic manager would not know how much it costs to provide healthcare services for BPJS patients and also whether the capitation fund have been adequately covered the cost of BPJS patients' medical treatment.

Studies have been conducted in order to calculate several disease-specific costs. It turns out that for several diseases the costs exceeded the insurance claim payments received (listed in INA-CBG's, an Indonesia Diagnosis-Related Group), while others were below the reimbursement. Yet, in order to calculate the cost continuously, a health care provider needs an information system. A well-designed costing information system will be able to provide actionable cost information, so that health care providers will be able to contain costs effectively, based on reliable and relevant cost information.

This research therefore has two questions. The first is how to calculate patient treatment costs and to allocate indirect costs at Ismail Medika Clinic. This question needs to be answered first because system development requires an understanding of the business process. In this study, we need to choose the most suitable costing method for Ismail Medika Clinic. The second research question is how to design a costing information system for the clinic using information system development tools.

In order to answer those research questions, a case study approach was taken with single unit analysis-Ismail Medika Health Clinic. This research is also a qualitative research using primary data. Data were acquired using the following instruments:

\section{A. Interview}

A semi-structured interview was conducted with the clinic manager in order to understand current business process at the clinic.

\section{B. Document Analysis}

This analysis considered relevant written information from the clinic.

\section{Observation}

By directly observing the processes at the clinic, we identified potential resources used in the process of patient care delivery.

To develop the information system, we used the framework for the application of systems technique (FAST) method. This method consists of eight steps, but this research only used four of them: scope definition, problem analysis, requirement analysis, and logical design.

This study outline consists of six parts: introduction, literature review, theoretical framework, research method, research findings and discussion, and a conclusion. The literature review will show relevant studies that will be used to answer the research questions, and the results of this research will be discussed at findings and discussion section. 


\section{LiterATURE REVIEW AND THEORETICAL FRAMEWORK}

\section{A. Literature Review}

Studies pertaining to health care cost accounting have been conducted by some researchers. Conteh and Walker (2004) used step-down cost accounting (SDCA) to calculate cost per patient or per ward. SDCA offers a relatively simple and practical approach to costing health care facilities. SDCA allocates indirect costs into final object cost (i.e., cost per patient), started from the top, which is total expense, divided by total output (i.e., the number of patient visits, number of inpatient days, or number of registrations). The result is average cost per patient visit. This SDCA approach can be simply applied because less data is required than what is used in other costing approaches. But according to Jadoo, Aljunid, Nur, and Ahmed (2015), the SDCA method produces less accurate cost information.

Another costing method is bottom-up or activity-based costing (ABC). Bottom-up costing records every item of service that a patient receives, and changes them into costs. Bottom-up costing gives more accurate results, but it requires a large investment of time and resources (Jadoo et al., 2015). Time-driven activity-based costing (TDABC) by Kaplan and Porter (2011) gives accurate cost information but it requires a lot of detailed data, e.g., time spent by doctors with patient and time spent by administration staff to serve patients.

For system development, an agile method - FAST - is used because of its comprehensive approach (Whitten \& Bentley, 2007). The FAST method consists of phases as follows (this study utilized the four early phases):

\section{1) Scope definition}

Scope definiton answers the question, "Is this problem worth looking at?" Assuming the problem is worth looking at, it establishes the size and boundaries of the project, the project vision, any constraints or limitations.

\section{2) Problem analysis}

Problem analysis studies the existing system and analyzes the findings to provide a more comprehensive understanding of the problems that triggered the project.

\section{3) Requirements analysis}

Requirement analysis defines and prioritizes the business requirements. We approach the business users to find out what they need or want out of the new system.

\section{4) Logical design}

Logical design translates business requirements into system models. The logical design will use system design tools like a functional decomposition diagram (FDD), an entity relationship diagram (ERD), a data flow diagram (DFD) , and a user interface design.

\section{Theoretical Framework}

Ismail Medika Clinic's business process faces too many difficulties in implementing TDABC. Services and items that patients receive may vary and, therefore, it is difficult to set a standard cost. We observe that time spent by a doctor to treat patient vary between doctors even though the medical treatment is just the same. Therefore, we instead used traditional $\mathrm{ABC}$ to allocate indirect costs in the clinic. The advantages of this approach are that data needed by the system are available at the clinic itself. The key is to use the right driver for the right resource.

Atkinson, Kaplan, Matsumura, and Young (2012) explained that to identify resource costs for various activities, an entity need to classify all activities according to the way in which the activities consume resources.

A unit-level activity is performed for each individual unit of product or service of the firm.

A batch-level activity is performed for each batch or group of units, whether products or services.

A product-level activity supports the production of a specific product or service.

A facility-level activity supports operations in general.

\section{RESEARCH METHOD}

This study uses a qualitative case study approach with Ismail Medika Health Clinic as the unit of analysis. A case study approach is applied to comprehend the phenomenon that occur in the unit analysis by considering multiple aspects. We obtain primary data by interview, observation, and content analysis. Interviews are conducted to learn about user system requirements and the clinic's business process related to patient care. We also observed the feasibility of utilizing an ABC method, i.e., whether it fits with the clinic's business process. Content analysis is conducted to analyze existing documentation at the clinic. After a big picture of patient care process is obtained, we go through all the data obtained in order to analyze and design the output of the study, which is a costing information system design. To validate the output, we also discuss the system design with the clinic manager to check the relevance of the system design and its flexibility in use.

The clinic is registered as a first-degree health care provider at BPJS Kesehatan. It was established in 2012, located in St. Caringin, Pancoran Mas, Depok. It has five separate treatment/cost centers:

- General Medical Ward

- Emergency Unit and In-patient Facility

- Maternity Ward

- Dentistry Clinic

- Laboratory

Figure 1 shows patient treatment activity flow at the Ismail Medika Clinic.

Based on our observation and an interview with the clinic manager, there are two types of expenditures in clinic, the first capital expenditures and the second operational expenditures. Clinic expenses are as follows:

- Fixed assets depreciation

- Medical devices and equipment depreciation

- Drugs 
- Medical and laboratory consumables

- Personnel expenses

- Inpatient service expenses

- Printing material and office stationery

- Personnel capacity improvement costs

- Facilities and infrastructure maintenance

- Utility costs

\section{RESEARCH FINDINGS AND DISCUSSION}

Before designing the costing information system, we calculated the costs in the general medical ward as an example, in order to see how the $\mathrm{ABC}$ method works in the clinic.

As we observed, there were four types of patient treatment direct costs involved:

(1) Medical Service or Jasa Medis, cost per medical treatment contributed to doctors and lab staff as they perform medical treatment for both regular and BPJS patients,

(2) Medical consumables

(3) Lab consumables

(4) Drugs

Table I shows the list of treatments and their direct costs in the general medical ward.

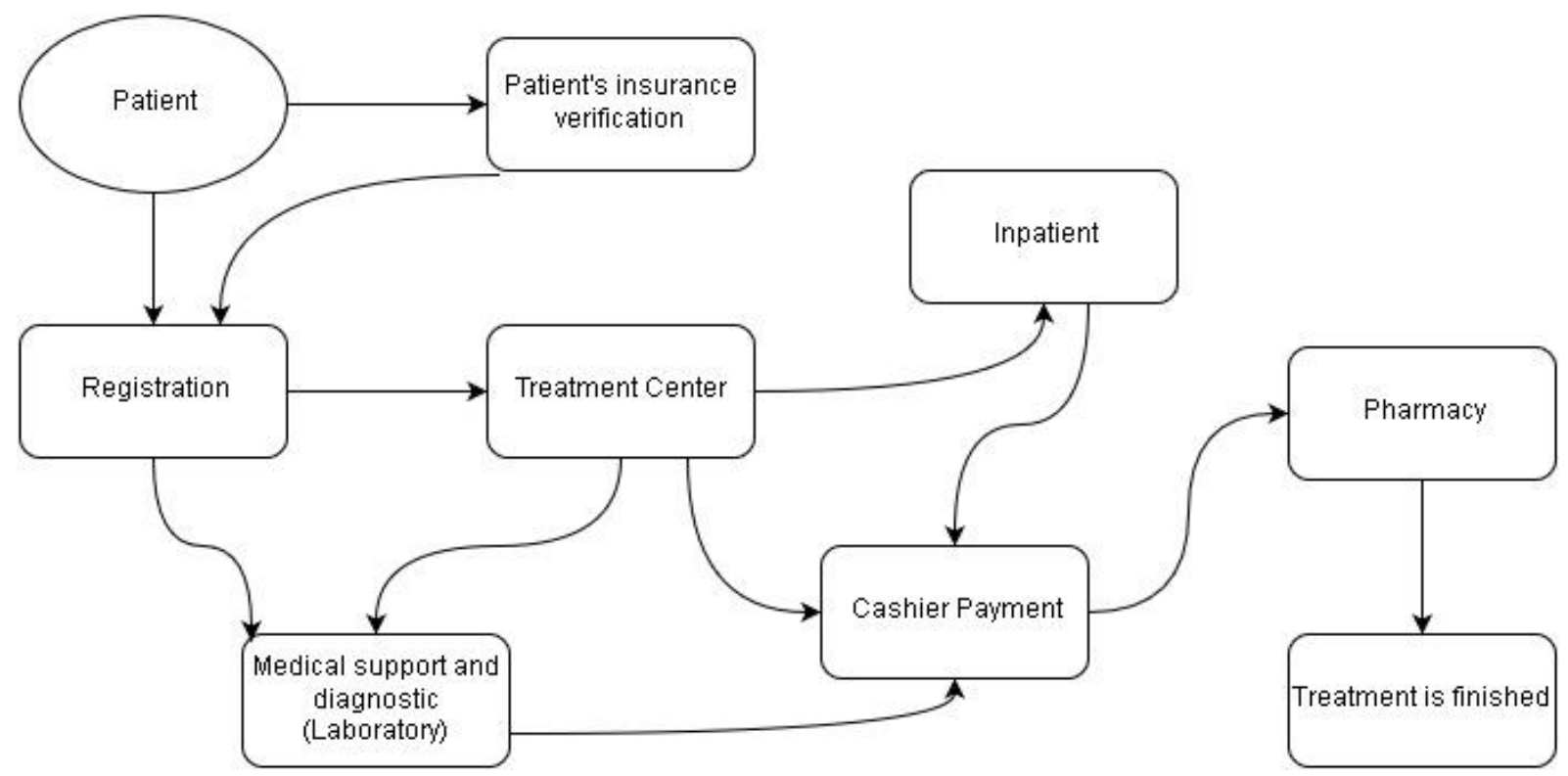

Fig.1. Patient Care Activity Flow

Table II shows indirect costs in the general medical ward. We did not put any cost into batch-level activity because there is no such cost that fits with batch-level activity characteristics. Costs are monthly costs that we identified from current clinic records and some are from interview results with the clinic's personnel.

After the fees have been identified for each cost element, we allocate these costs to each treatment or cost center. For this study, we allocated indirect costs for the general medical ward in the clinic. Table III shows the indirect cost allocation for the clinic's general medical ward. After indirect unit costs were identified, we then calculated unit costs for each treatment in the general medical ward shown in Table IV.

We then use the simulation of cost calculation above as part of costing system requirement analysis. Before we started the system development phase, we checked the compatibility of $\mathrm{ABC}$ method with the existing business process at the clinic.
Implementing and maintaining healthcare costing are continuously performed tasks that need to be done in a timely manner. A costing information system is developed to solve this problem. To answer the second question of this research, which is to analyze and design costing information system, the next part will discuss the process of designing costing information system using the FAST method.

\section{A. The Scope Definition Phase}

The scope definition phase is concerned primarily with the system owners' view of the existing system and the problems or opportunities that triggered the interest. System owners tend to be concerned with the big picture, not details. As shown in Table $\mathrm{V}$, the problems and opportunities of health care costing at the clinic were identified using a performance, information, economics, control, efficiency, and service (PIECES) framework. 
TABLE I. DIRECT COSTS IN GENERAL MEDICAL WARD

\begin{tabular}{|l|c|c|c|c|c|c|}
\hline No & Medical Treatment & $\begin{array}{c}\text { Drug } \\
\mathbf{s} \\
\text { (IDR }\end{array}$ & $\begin{array}{c}\text { Medical } \\
\text { Consumible } \\
\text { (IDR) }\end{array}$ & $\begin{array}{c}\text { Lab } \\
\text { Consumible } \\
\text { (IDR) }\end{array}$ & $\begin{array}{c}\text { Medical } \\
\text { Service } \\
\text { (IDR) }\end{array}$ & $\begin{array}{c}\text { Total Direct } \\
\text { Cost } \\
\text { (IDR) }\end{array}$ \\
\hline 1 & Rawatjalan & 20,00 & 0 & 0 & 8,000 & 28,000 \\
\hline 2 & Refraksi & 0 & 0 & 0 & 10,000 & 10,000 \\
\hline 3 & $\begin{array}{c}\text { Eksterpasi benda asing } d i \\
\text { kornea/conjunctiva }\end{array}$ & 1,000 & 2,500 & 0 & 20,000 & 23,500 \\
\hline 4 & Pengambilan serumen & 0 & 2,000 & 0 & 10,000 & 12,000 \\
\hline 5 & Nebulizer & 14,30 & 1,000 & 0 & 10,000 & 25,300 \\
\hline 6 & Keterangan sehat & 0 & 0 & 0 & 5,000 & 5,000 \\
\hline 7 & Pengambilan benda asing & 7,800 & 2,000 & 0 & 10,000 & 19,800 \\
\hline
\end{tabular}

TABLE II. INDIRECT COSTS IN GENERAL MEDICAL WARD

\begin{tabular}{|c|c|c|c|c|}
\hline Cost element & $\begin{array}{c}\text { Cost } \\
\text { (IDR) }\end{array}$ & Driver & Driver quantity & $\begin{array}{l}\text { Tariff } \\
\text { (IDR) }\end{array}$ \\
\hline \multicolumn{5}{|c|}{ Unit Level Activity Cost } \\
\hline Office stationery & 700,000 & Number of treatment & 2,700 & 260 \\
\hline \multicolumn{5}{|c|}{ Product Level Activity Costs } \\
\hline Administration cost & $9,000,000$ & Number of staff & 3 & $3,000,000$ \\
\hline \multicolumn{5}{|l|}{ Personnel cost } \\
\hline General medical ward & $\overline{14,000,000}$ & Number of staff & 4 & $3,500,000$ \\
\hline Emergency unit and inpatient facility & $14,000,000$ & Number of staff & 4 & $3,500,000$ \\
\hline Maternity ward & $19,000,000$ & Number of staff & 5 & $3,800,000$ \\
\hline Dentistry clinic & $11,000,000$ & Number of staff & 3 & $3,666,666$ \\
\hline Laboratory & $6,000,000$ & Number of staff & 2 & $3,000,000$ \\
\hline \multicolumn{5}{|c|}{ Facility Level Activity Costs } \\
\hline Utility cost & $1,500,000$ & Floor area & 375 & 4,000 \\
\hline Cleaning cost & 500,000 & Floor area & 375 & 1,333 \\
\hline Building maintenance cost & 300,000 & Floor area & 375 & 800 \\
\hline Med equipment maintenance cost & 250,000 & Floor area & 375 & 667 \\
\hline Equipment depreciation & $4,500,000$ & Floor area & 375 & 12,000 \\
\hline USG device depreciation & 500,000 & Number of USG treatment & 450 & 1,111 \\
\hline Building depreciation & 450,000 & Floor area & 375 & 1,200 \\
\hline
\end{tabular}

TABLE III. INDIRECT COSTS IN THE GENERAL MEDICAL WARD

\begin{tabular}{|c|c|c|c|c|}
\hline No. & Cost Element & Driver Quantity & Fees (Tariffs) & Cost \\
\hline A. & \multicolumn{3}{|c|}{ Product Level Activity Costs } & $17,000,000$ \\
\hline 1. & Administration cost & 1 & $3,000,000$ & $3,000,000$ \\
\hline 2. & Personnel cost & 4 & $3,500,000$ & $14,000,000$ \\
\hline B. & \multicolumn{3}{|c|}{ Facility Level Activity Costs } & $1,260,000$ \\
\hline 1. & Utility cost & 63 & 4,000 & 252,000 \\
\hline 2. & Cleaning cost & 63 & 1,333 & 83,979 \\
\hline 3. & Building maintenance cost & 63 & 800 & 50,400 \\
\hline 4. & Medical equipment maintenance costs & 63 & 667 & 42,021 \\
\hline 5. & Equipment depreciation & 63 & 12,000 & 756,000 \\
\hline 6. & Building depreciation & 63 & 1,200 & 75,600 \\
\hline C. & \multicolumn{3}{|c|}{ Sum of product level and facility level activity costs $(\mathrm{A}+\mathrm{B})$} & $18,260,000$ \\
\hline D. & \multicolumn{3}{|c|}{ Driver amount (Number of treatments) } & 700 \\
\hline E. & \multicolumn{3}{|c|}{ Cost per unit product level and facility level activity cost (C:D) } & 26,086 \\
\hline F. & \multicolumn{3}{|c|}{ Office stationery } & 260 \\
\hline G. & \multicolumn{3}{|c|}{ Indirect cost per unit for Pelayanan Rawat Jalan/Poli Umum $(\mathrm{E}+\mathrm{F})$} & 26,346 \\
\hline
\end{tabular}


TABLE IVINDIRECT UNIT COSTS FOR TREATMENT IN GENERAL MEDICAL WARD

\begin{tabular}{|c|c|c|c|c|}
\hline No. & Medical Treatment & $\begin{array}{l}\text { Direct Cost } \\
\text { (IDR) }\end{array}$ & $\begin{array}{c}\text { Indirect Cost } \\
\text { (IDR) }\end{array}$ & $\begin{array}{c}\text { Total Cost } \\
\text { (IDR) }\end{array}$ \\
\hline 1. & Rawat jalan & 21.000 & 26.346 & 47.346 \\
\hline 2. & Refraksi & 5.000 & 26.346 & 31.346 \\
\hline 3. & $\begin{array}{c}\text { Eksterpasi benda asing di } \\
\text { kornea/conjunctiva }\end{array}$ & 23.500 & 26.346 & 49.846 \\
\hline 4. & Pengambilan serumen & 7.000 & 26.346 & 33.346 \\
\hline 5. & Nebulizer & 20.300 & 26.346 & 46.646 \\
\hline 6. & Keterangan sehat & 5.000 & 26.346 & 31.346 \\
\hline 7. & Pengambilan benda asing & 19.800 & 26.346 & 46.146 \\
\hline
\end{tabular}

TABLE V.

IDENTIFICATION OF PROBLEMS AND OPPORTUNITIES USING A PIECES FRAMEWORK

\begin{tabular}{|l|l|}
\hline Performance & Opportunity: Continuous and automated cost calculation \\
\hline Information & Problems: \\
& (1) Lack of relevant patient cost information. \\
& (2) Inaccurate cost information. \\
& (3) Difficulties in producing cost information. \\
& (4) Inadequate data to perform patient cost calculation. \\
\hline Economics & Problems: \\
& (1) Unknown patient treatment cost. \\
& (2) Untraceable patient treatment cost. \\
\hline Control & Problems: Without cost information, resources and cost related decision making could \\
& go wrong. \\
& Opportunity: Cost information will help clinic to contain its costs. \\
\hline Efficiency & Problem: Without a structured and automated costing system, excessive efforts are \\
& needed to produce cost information. \\
\hline Service & Opportunity: As a costing system is integrated with other systems, cost calculation \\
& processes would be faster. \\
\hline
\end{tabular}

Beside the problems and opportunities described above, we discussed the scope of this project with the clinic's manager. We agreed that this project will develop a system that is able to perform health care cost calculations and also to store data related to costing system.

\section{B. Problem Analysis Phase}

The goal of the problem analysis phase is to study and understand the problem domain well enough to thoroughly analyze its problems, opportunities, and constraints (Whitten \& Bentley, 2007). As identified in the PIECES framework, lack of relevant patient cost information and inadequacy of resources data are the root causes of the clinic's problem. Therefore, the system being proposed would be required to perform health care cost calculation and record information related to health care costing.

\section{Requirement Analysis Phase}

\section{1) Functional decomposition diagram}

To understand and define processes in the system, we draw an FDD (Functional Decomposition Diagram) to divide the system into logical subsystems and/or functions (Whitten \& Bentley, 2007). Figure 2 shows the FDD of clinic's costing information system. We separated the operational and reporting aspects of a system. Thus, we factored each subsystem accordingly. Subsystems are actually functional task groups that need to be done in performing the $\mathrm{ABC}$ method. There are five subsystems and each of them is actually derived from ABC steps. Most of the subsystems' tasks are to input the data required by the $\mathrm{ABC}$ method.

\section{Logical Design Phase}

As we continue to the fourth step of the FAST method, a logical design further documents business requirements using system models that illustrate data structures (i.e., data modeling) and data flows (i.e., process modeling). In a sense, they validate the requirements established in the previous phase (Whitten \& Bentley, 2007). The logical design approach is used to structure the functional requirements. This means that, we draw system models to illustrate the functional requirements. These include a combination of data and process that represent the business and user requirements. This task is triggered by each functional requirement drawn in the FDD (Figure 2).

\section{1) Process modeling}

\section{a) Contextual Data Flow Diagram}

For the process modeling, we first documented the initial project scope. Whitten and Bentley (2007) explained that a project's scope defines what aspect of the business a system or application is supposed to support and how the system being modeled must interact with other system and the business as a whole. Scope is defined as the communication focus from the system owner's perspective. It is documented with a context data flow diagram, also called an environmental model. Figure 3 shows a context data flow diagram for the costing information system. 
The context data flow diagram contains only one process. External agents (i.e., clinic's personnel) are drawn around the perimeter. Data flows define the interactions of a system with the boundaries and with the external data stores (Whitten \& Bentley, 2007). However, the costing information system only interacts with external agents without any external data store. It exists in that form because all of the data required by the system will be provided by these external agents. Internal data stores will be in the system itself. As shown in Figure 4, the main purpose of costing information system is to process all the data input and produce patient cost and capacity reports as system outputs to the clinic manager.

\section{a) System Diagram (Level 1 DFD)}

A Level 1 DFD is "exploded" from the single process created on the original context diagram (Figure 3). Because of the small size of costing information system, a single diagram actually can be drawn to show all the events for the system. Figure 4 shows a DFD for costing information system. Level 1 DFD shows all the events for the system. Events are actually derived from the actual $\mathrm{ABC}$ steps. Connections between subsystems are also shown in the Level 1 DFD.

\section{1) Data modeling}

Data modeling or database modeling organizes and documents a system's data. There are several notations for data modeling. The actual model is usually called an ERD (Entity Relationship Diagram) because it represents data in terms of the entities and relationships described by the data (Whitten \& Bentley, 2007). If we look at Figure 4 (Level 1 DFD), there are twelve data stores in the system. In a data model, those data stores are called entities. An entity is a class of persons, objects, or concepts about which we need to capture and store data. We then identify what specific pieces of data the business require to store about each instance of a given entity. These pieces of data (attributes) are descriptive properties or characteristics of entities.

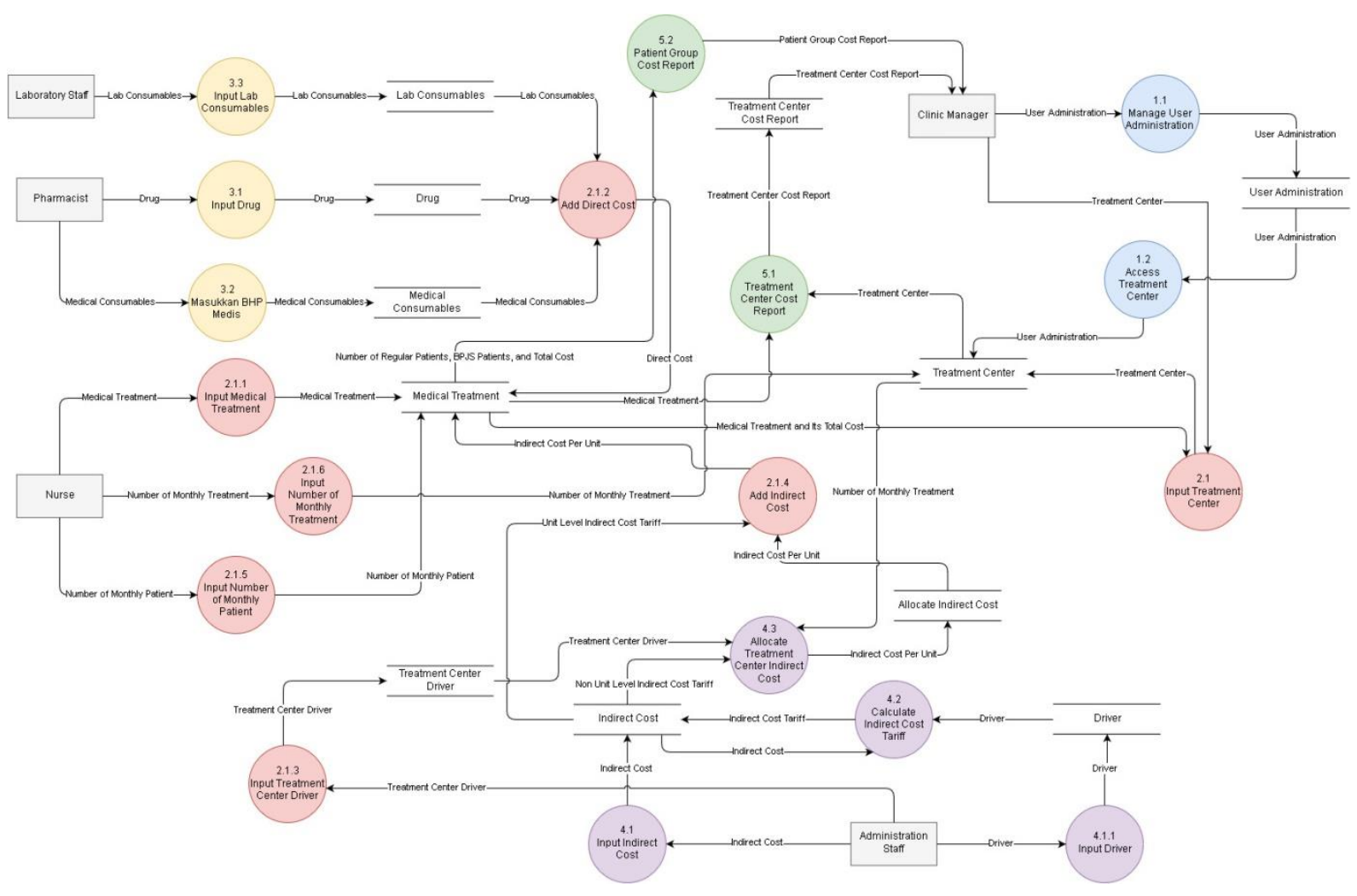

Fig.4. Level 1 DFD 


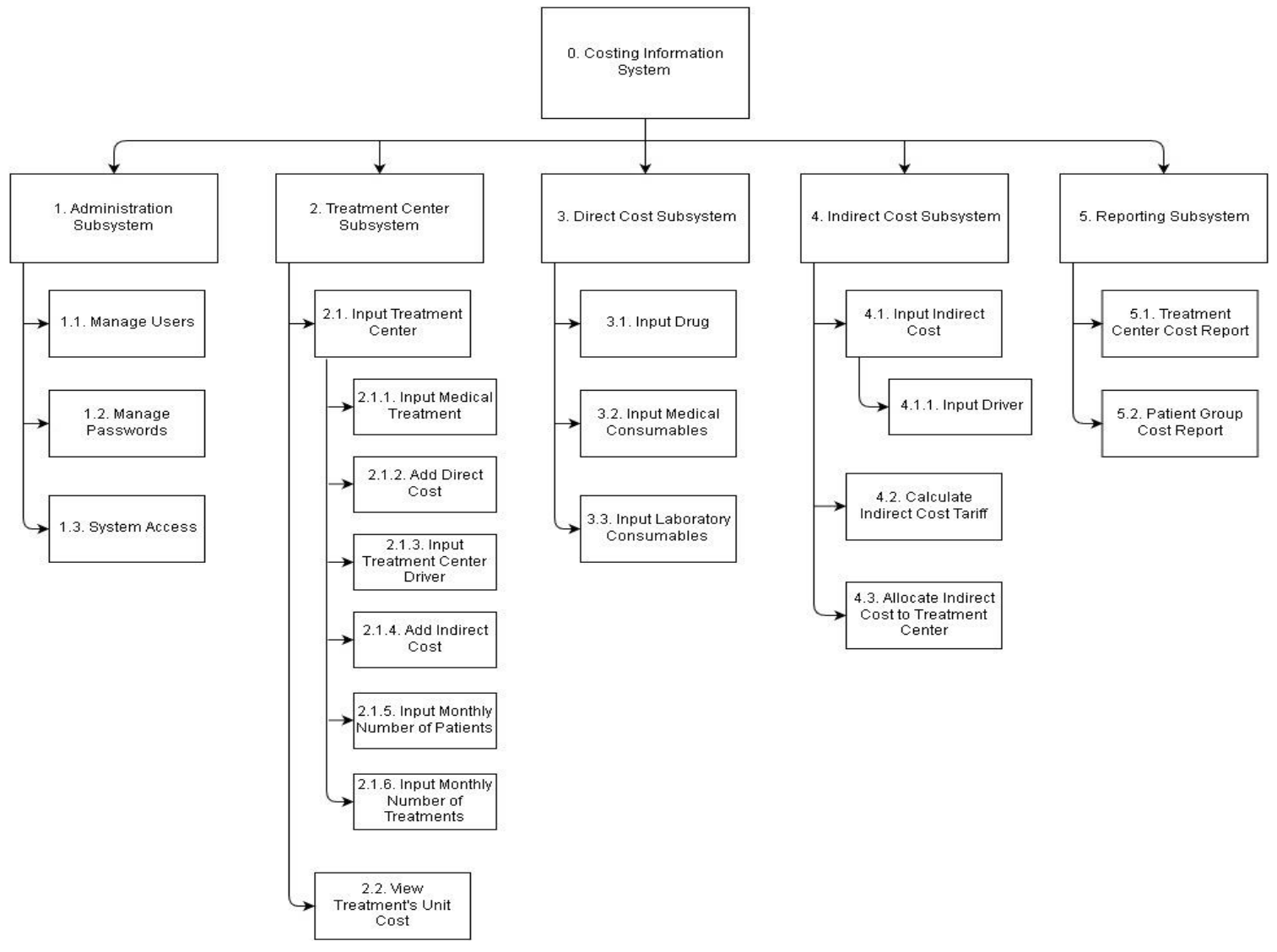

Fig.2. Functional Decomposition Diagram

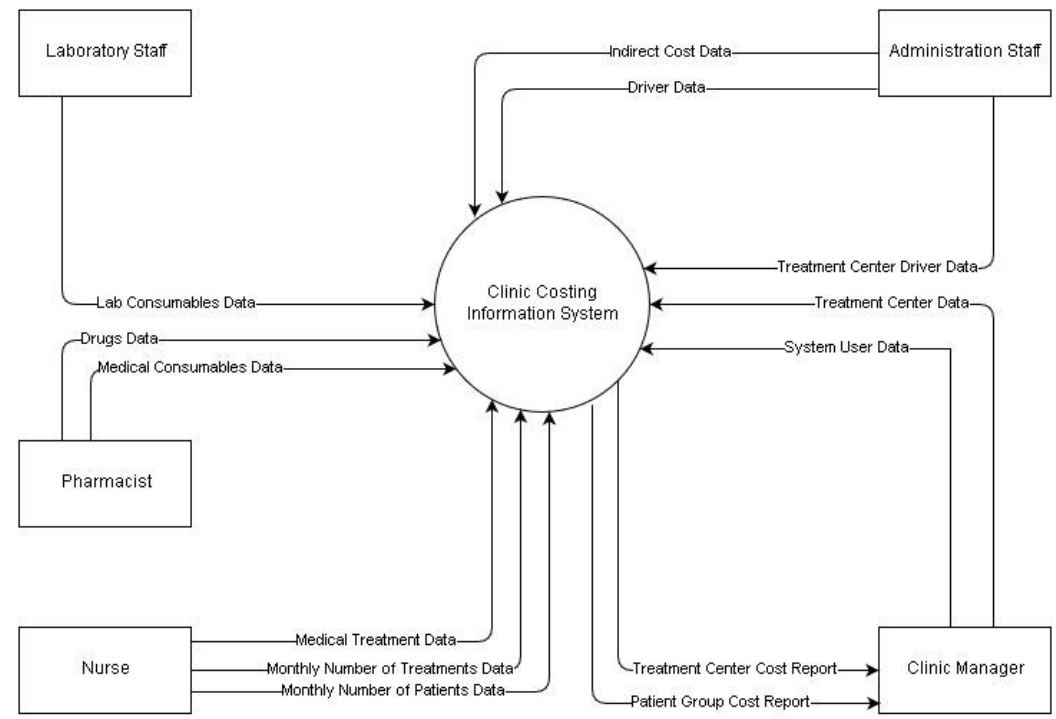

Fig.3. Contextual Diagram

TABLE VI CARDINALITY NOTATIONS

\begin{tabular}{|l|c|c|c|}
\hline $\begin{array}{c}\text { Cardinality } \\
\text { Interpretation }\end{array}$ & $\begin{array}{c}\text { Minimum } \\
\text { Instances }\end{array}$ & $\begin{array}{c}\text { Maximum } \\
\text { Instances }\end{array}$ \\
\hline $\begin{array}{l}\text { Exactly one (one } \\
\text { and only one) }\end{array}$ & 1 & 1 & Graphic Notation \\
\hline Zero or one & 0 & 1 & Many $(>1)$ \\
\hline One or more & 1 & Many $(>1)$ & \\
\hline Zero, one or more & 0 & $>1$ & \\
\hline More than one & $>1$ & & \\
\hline
\end{tabular}




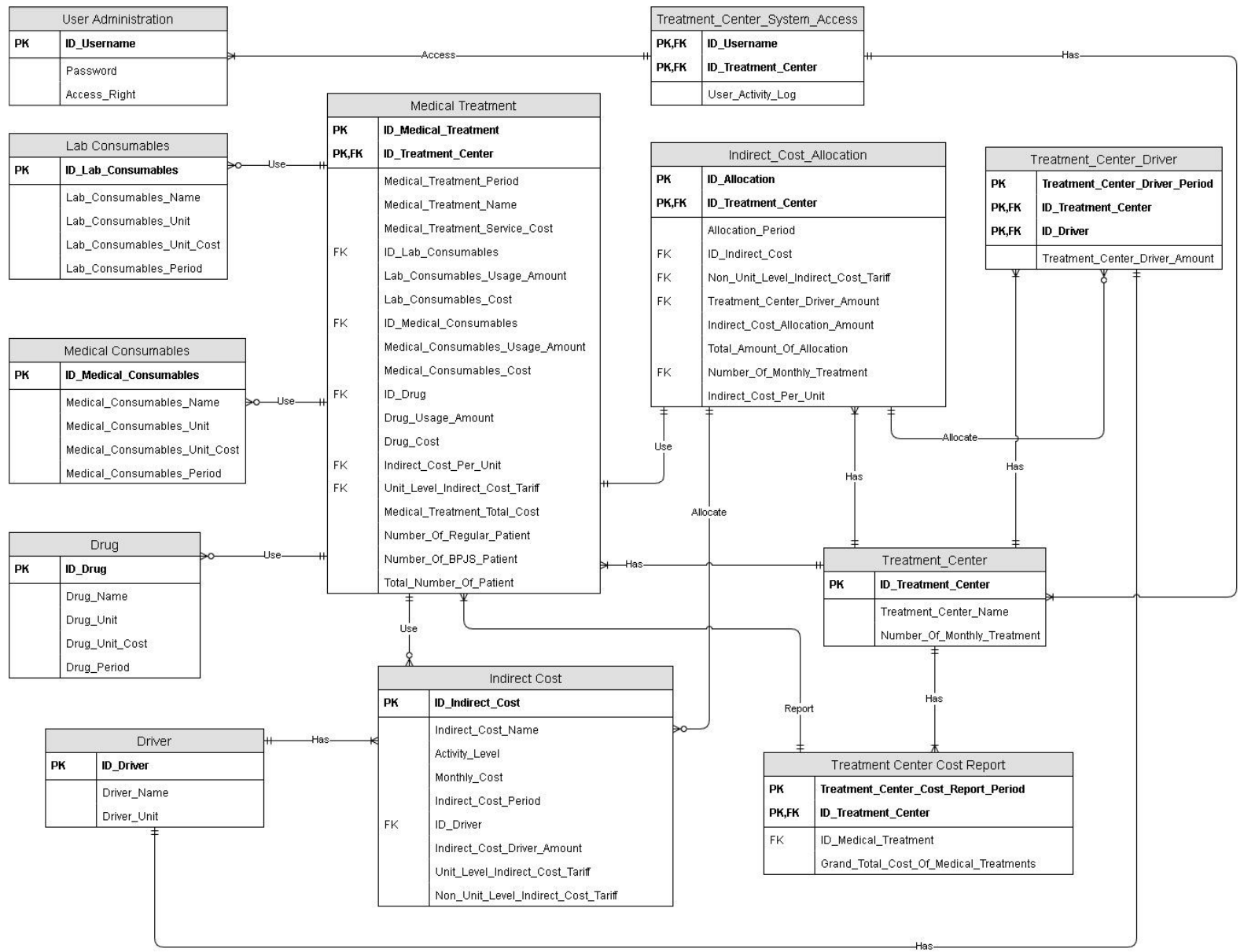

Fig.5. Entity Relationship Diagram

Costing information system's ERD is shown in Figure 5. All data stored in Level 1 DFD actually consists of attributes listed in all the entities shown in the ERD.

An entity has many instances, there exists a need to uniquely identify each instance based on the data value of one or more attributes. For example, the entity patient will be input continuously to the system because every day, generally, new and different patients will come to clinic. Thus, every entity must have a key that uniquely identifies it. A primary key $(\mathrm{PK})$ is a candidate key that will be used to uniquely identify a single entity instance (Whitten \& Bentley, 2007). For example, "ID_Username" is the PK for the "User Administration". Conceptually, entities and attributes do not exist in isolation. The things they represent interact with and impact one another to support the business mission. Thus, Whitten and Bentley (2007) introduced the concept of relationship. A relationship is a natural business association that exists between entities. The relationship may represent an event that links the entities or merely a logical affinity that exists between entities, e.g., the entity's supporting resource cost and supporting resource driver. We make the following business assertions that link supporting resource and its driver: each supporting resource has one supporting resource driver. The verb has defined the business relationship that exists between the two entities. The last important concept in data modeling is about cardinality. Cardinality is the minimum and maximum number of occurrences of one entity that may be related to a single occurrence of the other entity (Whitten \& Bentley, 2007). Table 6 shows cardinality notations.

\section{DISCUSSION}

The first question of this study deals with how to calculate costs and allocate indirect costs at the clinic. This question needs to be answered because system development requires an understanding of the business process. The second is how to design a costing information system for the clinic using information system development tools. We referred to activity-based costing (ABC) methods the cost allocation method. We then checked the compatibility of ABC method, whether it can be implemented at our unit of analysis - the Ismail Medika Health Clinic.

To answer the second question, we used the FAST method. Developing an information system using that method is actually quite agile. Agile development is a systems development strategy wherein the system developers are given the flexibility to select from a variety of appropriate tools and techniques in order to best accomplish the tasks at hand (Whitten \& Bentley, 2007). In this research, we first used the FDD to divide the system into logical subsystems and/or functions. Subsystems in the FDD are actually functional task groups that need to be done in performing TDABC. There are five subsystems and each of them is actually derived from the ABC method. Most of the subsystems' tasks entail inputting the data required by $\mathrm{ABC}$ method. In some other system development processes, including Whitten and Bentley (2007), an FDD is drawn in process modeling phase. But we select FDD as our first model because its ability to give a big picture of the system's functions and it is easy to understand. 
Process modeling shows contextual diagram and DFD. Contextual diagram is a DFD that shows a big picture of the system. That one process in context diagram then can be "exploded" into a Level 1 DFD. Each process shown in the Level 1 DFD is actually derived from the ABC method. Processes are grouped based on their subsystems as drawn in FDD. The last model is a data scheme, using the ERD, which summed up the attributes of data stores showed in the DFD. ERD also shows relationships and cardinalities between entities in the system.

\section{CONCLUSION}

As a result of this system design implementation, hopefully after the physical development of this system is done, the clinic manager will actually be able to receive a patient cost report and treatment or cost center report. A patient cost report can be printed based on patients' payment method group so that, with respect to patients using the BPJS payment method, total costs will be known. After some period, the clinic manager will be able to review clinic's capitation fund adequacy, whether it covers monthly BPJS patients total costs or not in particular. Any cost that exceeds or goes beyond set standards, can be traced to its source or center. The limitation of this study is that this research only takes into account early phases of the FAST method. For further study, two suggestions may be set forth. First, develop the system physically; second, widen the research scope by incorporating other costing management tools into the system.

\section{REFERENCES}

[1] Conteh, L., \& Walker D. (2004). Cost and Unit Cost Calculation Using Step-down Accounting. Health Policy and Planning. 19 (2), 127-135. doi: 10.1093/heapol/czh015 [Accessed 10th May 2018]

[2] Jadoo, S.A.A., Aljunid, S.M., Nur, A.M., \& Ahmed, Z. (2015). Development of MY-DRG Case-Mix Pharmacy Service Weights in UKMMC in Malaysia. DARU Journal of Pharmaceutical Sciences, 23(1), 14. doi: 10.1186/s40199-014-0075-4

[3] Kaplan, R., \& Porter, M.E.. (2011). How to Solve the Cost Crisis in Health Care. Harvard Business Review, 89(9), 46-52, 54, 56-61.

[4] Whitten, J.L., \& Bentley, L.D. (2007). System Analysis and Design Methods (7th Ed.). New York, NY: McGraw-Hill Company

[5] Fearon, G. (2009). Economics of public good provision: auditing, outsourcing, and bribery. Canadian Journal of Economics, 42(3), 9971022.

[6] Atkinson, A. A., Kaplan, R. S., Matsumura, E. M., \& Young, S. M. (2012). Management Accounting: Information for Decision Making and Strategy Execution (6th ed.). New York, NY: Pearson.

[7] Indonesian Ministry of Health. (2016). Standar Tarif Pelayanan Kesehatan dalam Penyelenggaraan Program Jaminan Kesehatan (Peraturan Kementerian Kesehatan Nomor 52 Tahun 2016). Jakarta, Indonesia: Indonesian Ministry of Health. 